\title{
ARTIFICIAL NEURAL NETWORK MODELLING OF VIBRATION IN THE MILLING OF AZ91D ALLOY
}

\author{
Ireneusz Zagórski', Monika Kulisz² ${ }^{2}$ Aleksandra Semeniuk³, Anna Malec ${ }^{3}$ \\ 1 Department of Production Engineering, Faculty of Mechanical Engineering, Lublin University of Technology, \\ Nadbystrzycka 36, 20-618 Lublin, Poland, e-mail: i.zagorski@pollub.pl \\ 2 Department of Organisation of Enterprises, Faculty of Management, Lublin University of Technology, \\ Nadbystrzycka 38, 20-618 Lublin, Poland, e-mail: m.kulisz@pollub.pl \\ 3 Student of Production Engineering, Faculty of Mechanical Engineering, Lublin University of Technology, \\ Nadbystrzycka 36, 20-618 Lublin, Poland, e-mail: aleksandra.semeniuk@pollub.edu.pl, anna.malec@pollub. \\ edu.pl
}

Received: 2017.05.15 Accepted: 2017.08.01 Published: 2017.09.03

\begin{abstract}
The paper reports the results of artificial neural network modelling of vibration in a milling process of magnesium alloy AZ91D by a TiAlN-coated carbide tool. Vibrations in machining processes are regarded as an additional, absolute machinability index. The modelling was performed using the so-called "black box" model. The best fit was determined for the input and output data obtained from the machining process. The simulations were performed by the Statistica software using two types of neural networks: RBF (Radial Basis Function) and MLP (Multi-Layered Perceptron).
\end{abstract}

Keywords: magnesium alloys, high-speed dry milling, vibration, chatter in milling, simulation, artificial neural networks.

\section{INTRODUCTION}

The knowledge of phenomena in machining processes is of vital importance. One particularly undesired phenomenon is vibration, particularly self-excited vibration known as chatter which occurs between the tool and the workpiece due to temporary surface imbalance. Vibration results in a lower quality of the machined surface, dynamic tool wear and even damage of machine tool components. The occurrence of vibration in the milling process can also lead to decreased machining efficiency $[1,25]$. What is more, besides exerting a negative effect on the human body, excessive vibration can significantly contribute to the destabilization of the production process [16].

Taking the above into consideration, the key problem is to determine such conditions of the milling process which will prevent vibration and thus ensure stability of this process. As a result, different types of specialist software are applied, enabling the users to apply parameters which ensure machining stability. In terms of process stability, the most important parameters include the cutting depth $\mathrm{a}_{\mathrm{p}}$ and the rotational speed $\mathrm{n}$. Given the advancement of cutting tools, machine tools and materials, special attention should be paid to the control and modelling of the cutting process. New methods are sought that could ensure reduced vibration of the cutting tools and workpiece $[21,25]$. Vibration is a typical by-product of technological operations and treatment, and is difficult to eliminate completely. However, there are many techniques for preventing self-excited vibration. Such techniques include numerical simulations and process dynamics modelling, the use of actuators, changing rotational speed frequency or increasing feed per tooth rate [15]. According to Quintan and Ciuran [14], the methods for preventing vibration can be divided into two main groups. The first group includes techniques that ensure machining stability via the selection 
of parameters from the stability lobe diagram and those that utilize the so-called lobbing effect. This group includes both out-of-process methods (methods focusing on the prediction, estimation and identification of SLDs by process modelling; analytical and experimental methods; machining processes modelling) and in-process methods (process and signal monitoring via the use of e.g. sensors).

The other group of vibration-preventing techniques includes all methods that involve changes in the behaviour of a system and modification of the stability limit. Here, one can distinguish active methods that focus on active modification of system behaviour, e.g., by changing the feed rate or rotational speed of the spindle, and passive methods which require the implementation of changes in the design of the cutting tools or the use of additional devices mounted on the machine components. The work [12] overviews a wide spectrum of techniques for damping chatter vibration; it also describes the way of selecting a given vibration damping method depending on various aspects of the machining process such as material workability and stiffness of the machine tool-chuck-workpiece-tool system. The work also describes how to design a stable process using stability lobe diagrams. The diagram was made using a stability model based on the cutting force components, dynamic and technological parameters of the process, and tool geometry.

\section{THE STATE OF KNOWLEDGE}

Vibrations occurring in the machine toolchuck-workpiece-tool system can be divided into two groups: vibrations that are not related to the machining process and vibrations that are caused by the machining process. Taking into account the source of vibration, vibrations can be divided into free, forced and self-excited. The main causes of self-excited vibration in the machining process include: envelope feedback between the parameters of working movements and the mass-dissipation-elastic machine tool-chuck-workpiecetool system, feedback by trace machining (trace regeneration or regenerative effect) as well as the friction between the workpiece and the tool and chip [18]. To account for the phenomenon of vibration reproduction, one can resort to the external and internal modulation of a machined layer thickness. After one revolution of the workpiece or an incomplete revolution of the end mill, the "wave" notched in the previous tool pass (internal modulation) becomes an external modulation, leading to an additional variation in the machined layer thickness. The above external modulation is a source of external excitation (variations in the cutting force), to which the machine tool-chuckworkpiece-tool system responds with vibration of the same frequency, phase-delayed [3]. To ensure the stability of the milling process and high-speed machining, the feed rate should always correspond to the total numerical ratio of chatter and tool rigidity [4]. In this way, one can minimize the regenerative effect and thus ensure the stability of the machining process.

One can distinguish many factors affecting the stability of a milling process. The most important include: machining strategy, type of machine tool, chucks, tool and its mounting, workpiece, cooling and lubrication of the tool-workpiece contact zone, and technological parameters. The study [25] investigated the stability of a 5-axis milling process for a rotor made of aluminium alloy $\mathrm{AlMgSiO}_{5}$. The tool rigidity and the rotor element were examined to determine the frequency of free vibration. Using ShopPro, a stability lobe diagram for the analysed process was produced and experimental tests were conducted of the milling process for a rotor combined with simultaneous measurement of vibration. The results demonstrate that under unstable conditions the amplitude of vibration increases even by 5 times, which affects the surface quality after machining. Stability analyses are often performed for thin-walled parts made of aluminium alloys such as EN AW-7075 T6 [17, 22], EN AW-2024-T351 [2] and EN AW-6061-T6 [23, 24]. The works $[17,18]$ investigate acceleration and cutting force components to determine the stability limit for parts with a varying (decreasing) thickness of the wall. Recurrence plots were made and recurrence quantification analysis (RQA) was performed. Variations in the modal parameters of the cutting process for thin-walled parts are significant for predicting stability diagrams. Modal weight, rigidity and damping ratio are vital, too. Stability indices such as recurrence rate (RR), determinism (DET), laminarity (LAM), divergence (DIV), length of the longest diagonal Line $\left(\mathrm{L}_{\max }\right)$, diagonal line segment distribution $\left(\mathrm{L}_{\text {ent }}\right)$ can be used to determine limit stability. The paper [18] employs the classical modal analysis and recurrence plots to investigate, using the CutPro software, the stability of a milling pro- 
cess for aluminium alloy EN AW-7075 by a PCD end mill (GuhringWNR-05492-16) with $16 \mathrm{~mm}$ in diameter. RP is a method for locating recurrent patterns and structural changes in a system. This technique ensures qualitative interpretation of hidden patterns in the dynamic systems based on the reconstruction of phase space. The following were used: RQA, stability indices: DET, LAM, DIV, $\mathrm{L}_{\mathrm{ENT}}, \mathrm{V}_{\mathrm{ENT}}$, and SLD plots. The study demonstrated that, compared to the classical modal analysis, the RP method yields better results that can be shown in a simplified form as stability indices. In addition, it is suggested that the classical modal analysis is not sufficiently effective in assessing stable regions.

The analysis was performed using a nonlinear model of milling described by two degrees of freedom, taking account of the nonlinear phenomena and susceptibility of the tool and workpiece moving in the same direction. To select the technological parameters ensuring stable machining for the depth of cut $a_{p}=0.5 \mathrm{~mm}$ and the rotational speed $n=3000$ revolutions per minute, stability lobe diagrams were made. After that, the effect of the external force was investigated for the above parameters. The results of previous research demonstrate that such parameters are typical of unstable machining. The closed loop control involved the use of a proportionate-integral PD controller. Due to the use of external force, suitable values of the technological parameters (based on stability diagrams) and the PD controller, the vibration clearly decreased.

The paper [20] describes the use of an external force to control the milling process in an open and closed loop. The numerical analysis was performed in Matlab-Simulink by the fourthorder Runge-Kutta method with variable step integration. A nonlinear model with two degrees of freedom was employed, taking into account the phenomena occurring during the process as well as the susceptibility to nonlinearity of the tool and the workpiece rotated in the same direction. In order to select process parameters that would ensure stable machining for the cutting depth ap of $0.5 \mathrm{~mm}$ and the rotational speed $\mathrm{n}$ of 3000 revolutions per minute, stability diagrams were determined and the impact of the external force was investigated. The results demonstrate that the parameters match an unstable machining process. With the closed-loop control a proportional integrating controller PD is used._By applying the external force, proper technological parameters and using the PD controller, the level of vibration was significantly reduced.

The stability of a milling process can also be investigated with the following methods [22]: chase plane method, Poincare's method and spectra analysis. This paper discusses the relationship between the maximum Lyapunov exponent and the spindle speed and milling depth. Finally, taking the maximum Lyapunov exponent as a criterion, the study determines the chatter stability domain of milling by the contour method. The maximum Lyapunov exponent increases with increasing the milling depth. The maximum Lyapunov exponent of vibration signal equal 0.61 is taken as a milling chatter nonlinear criterion. In addition, the maximum Lyapunov exponent of the workpiece vibration signal processing can be a means of optimizing the processing parameters.

The stability analysis was also performed for thin-walled curvilinear elements made of materials such as EN AW-6061-T6.The modelling of vibration in the cutting zone can also be done by FEM simulation techniques. A new dynamic model of tool and workpiece system is proposed to consider the dynamic behaviour of tool and workpiece as well as the influences of engagement and tool feed direction. The numerical and experimental results demonstrate that chatter can be accurately predicted for the peripheral milling of a thin-walled workpiece [23]. The milling process of EN AW-6061-T6 alloy was performed by a cutter with a varying angle of helix inclination. Vibration (displacement) was analysed, the Poincaré section was designed, and Fast Fourier transform (FFT) analysis was performed in frequency spectrum. Another parameter that may be helpful in stability analysis is the so-called root mean square (RMS) of displacement. The irregular tool geometry (varying angle of inclination of the helix) may affect the modulation of regenerative effect and may have a positive impact on vibration damping [24]. The application of FEM to simulate the milling of EN AW-2024-T351 alloy can help determine the effect of tool vibration on chip morphology, cutting force, and surface topology. A hybrid dynamic cutting model (HDC) is proposed to predict chip morphology under dynamic cutting conditions. The numerical results show that higher values of cutting speed and uncut chip thickness are associated with higher vibration amplitudes [2]. The limit stability of a milling process can also be determined by methods containing so-called constant training algorithms. 
The paper [8] offers a new approach to assessing process stability by measuring acceleration signals. A multidimensional stability lobe diagram (MSDL) is used with two new algorithms of constant training. A new criterion in introduced which provides information about the quality of prediction for a given input region. The study was performed using a support vector machine and artificial neural networks. Pocket components are often manufactured for the aircraft industry. The stability of the milling process for such elements, often made of EN AW-7075 T6, has been investigated using a genetic search algorithm. A wide range of spindle speeds, feeds, depth and width of cuts are processed through a genetic search algorithm. The most optimal cutting condition set, which gives the shortest machining time while respecting the chatter, torque and power constraints, is determined [9]. It is also possible to produce three-dimensional stability lobe diagrams which provide vibration frequencies (except the basic parameters $a_{p}$ and $n$ ). The solid line (in three-dimensional stability lobe diagrams) can indicate the threshold value of stability limit [7].

An important factor affecting the stability of the milling process and production efficiency is suitable design of special milling tools using stability models. Stability analyses are often performed with respect to shank tools with the so-called "classical geometry" (straight cutting edge) or with a wave-shaped cutting edge at the tool perimeter (e.g. Kordell design geometry) [11]. Using the general dynamic model of the cutting force [6], numerical simulations were performed to investigate the stability of a milling process for aluminium alloy EN AW-7075-T6 using carbide mills with a wave-shaped (serrated) cutting edge and with a regular (straight) cutting edge. The diameter of the serrated tool was 20 $\mathrm{mm}$ and that of the regular tool was $16 \mathrm{~mm}$. the modelling was performed by the semi-discretization method which consists in transforming the models and equations of continuous functions into their discrete counterparts. In addition, a harmonic analysis in the Frequency Response Function (FRF) was performed. Based on these results, it was found that the regular cutters, in contrast to the serrated ones, generate periodically varying and uniform (repeatable in terms of value) cutting forces.

The above may be caused by an uneven distribution of loads between the grooves of the serrated tool. During the removal of material layer by serrated cutters, the machining efficiency can be higher (by increasing the depth of cut) due to a smaller cutting torque when compared to mill cutters with a straight cutting edge. The effect of tool geometry on stability of the milling process is also discussed in [5]. The experimental findings and numerical results served for devising an optimal design of varying geometry milling tools. The simulations were performed for a four-blade milling cutter with $12 \mathrm{~mm}$ in diameter and made of aluminium alloy EN AW-7075. The results demonstrate that the use of optimal helix inclination angle leads to higher stability of the machining process.

It is important that machining can be performed in the full range of process parameters without decreasing the cutting speed, feed rate or depth of cut, while at the same time maintaining the required machining accuracy. To this end, we often use active control of tool vibration. Vibration monitoring involves the control of physical quantities and the creation of temporary values of the control signal in accordance with the adopted monitoring strategy. This type of control entails not only passive observation of a negative phenomenon but also taking steps to prevent this phenomenon. The supervision and actions taken on its basis do not necessarily occur simultaneously [10].

Despite its many advantages, the machining of magnesium alloys poses several risks. During the process there may occur undesired phenomena such as built-up edge (on the tool flank or rake face), resulting from intensive adhesion. These phenomena can strongly affect variations in the cutting force components, which may, in turn, lead to decreased surface quality, reduced accuracy of size and shape, increased vibration and temperature during the machining processes. There is also a risk of self-ignition of magnesium, which can occur when the temperature suddenly increases in the cutting zone. Finally, magnesium dust produced during the machining has a negative effect on the health of the machine tool operating staff and the state of the machine tools alike $[11,13]$.

Therefore, the analysis of vibration and computer simulations can lead to enhanced stability, security and efficiency of magnesium alloy machining. The model enables choosing technological parameters in such a way as to obtain the lowest vibration, without causing any machining errors. During the milling process there may oc- 
cur temporary surface irregularities caused by vibrations between the tool and the workpiece. That is why it is important to define the conditions that will ensure a stable course of the treatment and help prevent vibration, especially self-excited vibration. Vibration modelling can be helpful in the design of a engineering decision support model in terms of technological parameters selection. The use of artificial neural networks allows us to predetermine the values of individual technological parameters and predicted values of vibration components. The numerical results provide positive evidence for the possible use of artificial neural networks in the design of nonlinear processes.

\section{METHODOLOGY, AIM AND OBJECT OF THE STUDY}

The modelling of vibration was performed for a milling process of magnesium alloy AZ91D. The process was performed using a TiAlN-coated carbide milling cutter with a smooth cylindrical grip used for the machining of $\mathrm{Al}$ and $\mathrm{Mg}$ alloys. The cutter had the following dimensions: $16 \times 25 \times 100$ $\mathrm{mm} \mathrm{W}-\mathrm{Z} 2, \lambda_{\mathrm{s}}=30^{\circ}$. The parameters were applied in the following ranges: $v_{c}=400 \div 1200 \mathrm{~m} / \mathrm{min}$, $\mathrm{f}_{\mathrm{z}}=0,05 \div 0,3 \mathrm{~mm} /$ tooth, depth of cut $\mathrm{a}_{\mathrm{p}}=0,5 \div 6 \mathrm{~mm}$. the width of milling was maintained constant at $\mathrm{a}_{\mathrm{e}}=14 \mathrm{~mm}$. The cutting process was performed on the vertical machining centre AVIA VMC800HS provided with the Heidenhain iTNC 530 control system, with the maximum rotational speed of the spindle $\mathrm{n}$ set to 24000 revolutions per minute and the maximum feed rate of $40 \mathrm{~m} / \mathrm{min}$.

The tools were mounted in the HSK63A SFD 16x120 holder from SECO. Before mounting the holders in the spindle cone, the holders were balanced using the CIMAT CMT-15V2N balancer, for the class G 2.5 at 25000 revolutions per minute according to ISO 1940: 2003. This standard allows for residual unbalance of as low as $1 \mathrm{~g} \mathrm{~mm}$ depending on the tool weight. For the TiAlN-coated carbide tool mounted in the thermo-shrinkable holder, the residual unbalance was $1 \mathrm{~g} \mathrm{~mm}$.

Vibration was measured using the SETAC (Triaxial Acceleration Computer) accelerometer manufactured by SEQUOIA, based on MEMS (Micro-Electro-Mechanical Systems). Installed on the machine tool, this device creates an autonomous system for triaxial monitoring of vibration during machining processes such as milling. The accelerometer was mounted on the vice in which the magnesium alloy specimen was fixed.

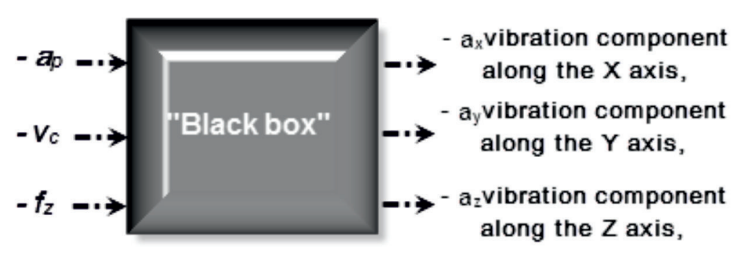

Fig. 1. General plan of the study - model of the milling process

The technical specifications of the accelerometer were as follows: measuring range $\pm 18 \mathrm{~g}$, dynamic range - from $85 \mathrm{~dB}$ to $10 \mathrm{~Hz}$, resolution - from 1 $\mathrm{mg}$ to $10 \mathrm{~Hz}$.

The variable parameters included: cutting speed $\mathrm{v}_{\mathrm{c}}$, feed per tooth $\mathrm{f}_{\mathrm{z}}$, cutting depth $\mathrm{a}_{\mathrm{p}}$ cutting width $a_{e}$, tool blade geometry. It can be assumed that the milling process is a kind of controllable object, wherein output parameters are the following vibration components: $a_{x}$ component along the $\mathrm{X}$ axis and $\mathrm{a}_{\mathrm{y}}$ component along the $\mathrm{Y}$ axis, and $\mathrm{a}_{\mathrm{z}}$ vibration component along the $\mathrm{Z}$ axis. The input variables included: cutting speed $\mathrm{v}_{\mathrm{c}}$, feed per tooth $\mathrm{f}_{\mathrm{z}}$ and cutting depth $\mathrm{a}_{\mathrm{p}}$, the remaining parameters were maintained constant during machining. A schematic model of this process is shown in Figure 1. The design of this process consists in the use of a so-called "black box" model to determine the best fit between input and output data obtained from the process. This solution was applied due to the complicated nature of the process. Such a model is used whenever it is difficult to determine mathematical equations describing a given process [11].

Assuming that the machining process for a given part is repeatable, it can be assumed that forced acceleration and cutting conditions at selected points of the tool path are repeatable, too. The accuracy of such an assumption requires that the cutting is done with a sharp instrument, at constant (for subsequent machining cycles) technological parameters of the cutting process.

\section{TEST RESULTS AND ANALYSIS - NEURAL NETWORK MODELLING}

The aim of modelling is to predict nonlinear processes (in this case, a milling process) using neural networks. These analyses can be used to create a system that would aid decision-making processes in a business company. For example, via selection of appropriate machining parameters, it is possible to ensure stable machining 


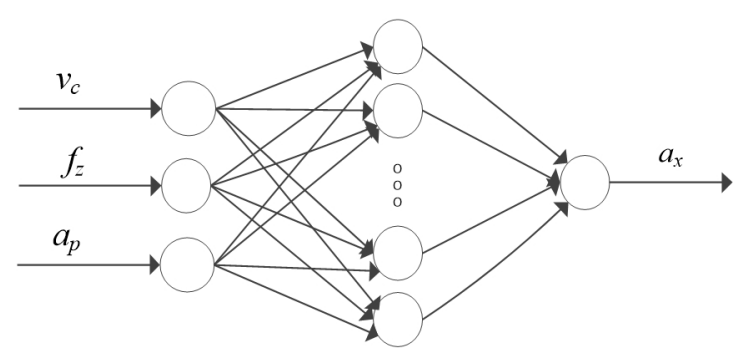

Fig. 2. Schematic design of an artificial neural network for vibration component along the $\mathrm{X}-\mathrm{a}_{\mathrm{x}}$ axis

and to eliminate vibration between the tool and the workpiece. This can result in, among others, enhanced efficiency of the machining process, a higher quality of the machined surface and lower tool wear.

The modelling of vibration components in the milling of AZ91D alloy using artificial neural networks was performed by the Statistica Neural Networks software. Two network types were modelled: Radial Basis Function (RBF) and Multi-Layered Perceptron (MLP). Every vibration component was modelled separately. Their values were calculated as an average of the maximum values from 10 intervals isolated from a region of stable machining, which was considered the output value of each model. The MLP network training was done by the Broyden-Fletcher-Goldfarb-Shanno (BFGS) method. The modelling of the MLP network was performed using the following activation functions: linear, exponential, logistic, tanh and sine. The training of the RBF network was performed by the RBFT method. The activation function of the RGB networks for hidden neurons had Gaussian distribution and for output neurons - linear function.

The modelling of vibration components milling AZ91D alloy using artificial neural networks performed using Statistica Neural Networks. The study analysed two networks: RBF (Radial Basis Function) and MLP (Multi-Layered Perceptron). Each vibration component was modelled separately. These values were calculated as an average of the maximum values of 10 separate compartments a stable machining area, representing an output value for each model. The MLP network training was done by the Broyden-Fletcher-Goldfarb-Shanno (BFGS) method. In the simulation, MLP uses the following activation functions: linear, exponential, logistic, tanh and sinus. Network RBF taught using methods RBFT. Activation function network RBG for hidden neurons is a Gaussian distribution, and the output neurons - linear function.

In order to ensure the simplest network design, the networks were built with one hidden layer. The input layer consists of three neurons (the cutting speed $v_{c}$, the feed per tooth rate $f_{z}$ and the depth of cut $a_{p}$ ) while the output layer had only one neuron (a relevant vibration component). The

Table 1. Parameters of the best MLP and RBF networks for the tested vibration components

\begin{tabular}{|c|c|c|c|c|c|c|c|}
\hline $\begin{array}{c}\text { Network } \\
\text { no. }\end{array}$ & $\begin{array}{l}\text { Network } \\
\text { name }\end{array}$ & $\begin{array}{c}\text { Quality } \\
\text { (training) [\%] }\end{array}$ & $\begin{array}{c}\text { Quality } \\
\text { (validation) } \\
{[\%]}\end{array}$ & $\begin{array}{c}\text { Error } \\
\text { (training) }\end{array}$ & Error (validation) & $\begin{array}{c}\text { Activation } \\
\text { (hidden) }\end{array}$ & $\begin{array}{c}\text { Activation } \\
\text { (output) }\end{array}$ \\
\hline \multicolumn{8}{|c|}{ Vibration component $a_{x}$} \\
\hline 1 & MLP 3-4-1 & $96,97 \%$ & $96,90 \%$ & 0,38 & 1,21 & Sine & Sine \\
\hline 2 & MLP 3-4-1 & $95,53 \%$ & $95,45 \%$ & 0,55 & 0,73 & Linear & Linear \\
\hline 3 & RBF 3-4-1 & $94,76 \%$ & $91,67 \%$ & 0,64 & 1,49 & Gaussian & Linear \\
\hline 4 & RBF 3-4-1 & $94,30 \%$ & $96,21 \%$ & 0,69 & 1,54 & Gaussian & Linear \\
\hline \multicolumn{8}{|c|}{ Vibration component $\mathrm{a}_{\mathrm{y}}$} \\
\hline 5 & MLP 3-4-1 & $99,70 \%$ & $91,34 \%$ & 0,02 & 1,16 & Logistic & Logistic \\
\hline 6 & MLP 3-6-1 & $99,70 \%$ & $91,32 \%$ & 0,02 & 1,15 & Logistic & Logistic \\
\hline 7 & RBF 3-4-1 & $90,62 \%$ & $86,01 \%$ & 0,48 & 0,77 & Gaussian & Linear \\
\hline 8 & RBF 3-4-1 & $91,77 \%$ & $99,55 \%$ & 0,42 & 1,35 & Gaussian & Linear \\
\hline \multicolumn{8}{|c|}{ Vibration component $\mathrm{a}_{\mathrm{z}}$} \\
\hline 9 & MLP 3-4-1 & $99,03 \%$ & $99,23 \%$ & 0,09 & 1,28 & Linear & Linear \\
\hline 10 & MLP 3-4-1 & $99,24 \%$ & $99,54 \%$ & 0,08 & 1,61 & Linear & Logistic \\
\hline 11 & RBF 3-4-1 & $82,15 \%$ & $98,75 \%$ & 1,57 & 0,14 & Gaussian & Linear \\
\hline 12 & RBF 3-4-1 & $84,43 \%$ & $98,95 \%$ & 1,39 & 0,65 & Gaussian & Linear \\
\hline
\end{tabular}


Table 2. Comparison of the actual values of the vibration component $\mathrm{a}_{\mathrm{x}}$ with the predicted values for selected cases of MLP 3-4-1

\begin{tabular}{|c|c|c|c|c|c|c|}
\hline $\mathrm{v}_{\mathrm{c}}$ & $\mathrm{f}_{\mathrm{z}}$ & $\mathrm{a}_{\mathrm{p}}$ & $\mathrm{a}_{\mathrm{x}}$ (experimental) & $\mathrm{a}_{\mathrm{x}}$ (numerical) & $\Delta$ & $\delta$ \\
\hline 400 & 0,15 & 6 & 11,15 & 11,22 & 0,08 & $0,68 \%$ \\
\hline 600 & 0,15 & 6 & 10,85 & 11,39 & 0,54 & $5,02 \%$ \\
\hline 800 & 0,15 & 6 & 11,86 & 11,45 & 0,41 & $3,46 \%$ \\
\hline 800 & 0,15 & 4,5 & 11,22 & 11,35 & 0,13 & $1,15 \%$ \\
\hline 800 & 0,15 & 3 & 10,41 & 10,32 & 0,08 & $0,82 \%$ \\
\hline 800 & 0,2 & 6 & 14,45 & 14,01 & 0,45 & $3,10 \%$ \\
\hline 800 & 0,25 & 6 & 15,95 & 16,25 & 0,30 & $1,90 \%$ \\
\hline 800 & 0,3 & 6 & 16,98 & 16,90 & 0,08 & $0,46 \%$ \\
\hline 1200 & 0,15 & 6 & 10,74 & 11,32 & 0,58 & $5,41 \%$ \\
\hline
\end{tabular}

number of training epochs $(200)$ and the number of neurons in the hidden layer $(3 \div 7)$ were selected experimentally. To simulate all three vibration components, we built 3 models of artificial neural networks. A schematic design of one of these networks for a vibration component in the direction $\mathrm{X}-\mathrm{a}_{\mathrm{x}}$ is shown in Figure 2. Schematic designs of other components are the same, each model output produces a relevant vibration component.

The experiments were conducted for 16 datasets of machining parameters, out of which 13 were used for network training. The training group was made of $80 \%$ of the measurement results while the validation group comprised of $20 \%$ of the results. As mentioned in [19], with small numbers of data sets it is possible to abandon the use of the so-called test group.

The most important indices of correct network selection are: training quality, validation quality, training error and validation error. The training and validation errors were determined by the least squares method. Every simulation involved experimental determination of 100 networks, out of which - based on the above indices -- 2 best networks per each tested network type (MLP and $\mathrm{RBF}$ ). Their parameters for individual vibration components $\left(a_{x}, a_{y}\right.$ and $\left.a_{z}\right)$ describing the milling process for AZ91D alloy are listed in Table 1. The results of the analysis of the neural network models demonstrate that among the tested vibration components the best results were obtained for the MLP network ( $a_{x}-$ Network 1: MLP 3-4-1 with four neurons, $a_{\mathrm{y}}-$ Network 6: MLP 3-6-1 with six neurons, $\mathrm{a}_{\mathrm{z}}$ - Network 10: MLP 3-4-1 with four neurons). The MLP 3-4-1 network for the component $a_{x}$ was obtained in 26 iterations, for $a_{z}-$ in 15 iterations, while the network MLP 3-6-1 for the component $\mathrm{a}_{\mathrm{y}}$ was obtained in 78 iterations. For the modelled components, the quality of the MLP network is higher than that of the RBF network, therefore it is recommended to use the MLP network.

To illustrate the accuracy of the modelled networks, Table 2 gives both the actual values of the vibration components and their predicted values for selected cases of the best network (MPL 3-41) and the component $a_{x}$ along with the values of relative and absolute error. As regards the actual values of the vibration components, the relative error does not exceed $7 \%$.

By the modelling of vibration components occurring during the AZ91D alloy milling by neural networks, it was possible to design models for calculating the values of individual components. Taking into consideration the afore-mentioned indices of correct network selection, below are the results of the modelling of vibration components versus cutting speed $\mathrm{v}_{\mathrm{c}}$ and feed per tooth $\mathrm{f}_{\mathrm{z}}$ : $\mathrm{a}_{\mathrm{x}}$ - Network 1: MLP 3-4-1 (Fig. 3), $a_{y}-$ Network 6: MLP 3-6-1 (Fig. 4) and $\mathrm{a}_{\mathrm{z}}$ - Network 10: MLP 3-4-1 (Fig. 5). Based on the results, it is possible to determine the values of individual vibration components $\left(a_{x}, a_{y}, a_{z}\right)$ with respect to given values of cutting speed $\mathrm{v}_{\mathrm{c}}$ and feed per tooth $\mathrm{f}_{\mathrm{z}}$. After importing the values of $v_{c}, f_{z}, a_{p}$ into Statistica, the programme returns the value of a relevant vibration component..

The designed models of neural networks are a tool enabling the determination of the maximum values of vibration components. The numerical results may be used to determine the technological parameters of machining processes for machine parts, especially in the case of non-linear processes. The simulation of the cutting force 


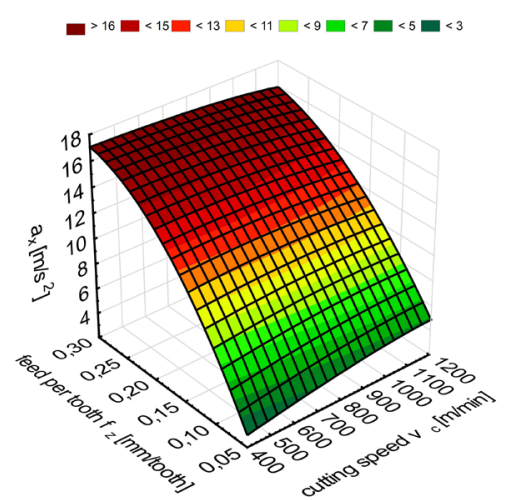

Fig. 3. Vibration component $a_{x}$ versus cutting speed $v_{c}$ and feed per tooth $\mathrm{f}_{\mathrm{z}}-$ MLP 3-4-1

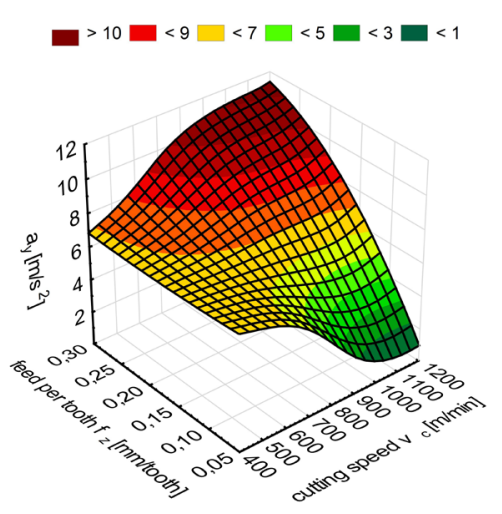

Fig. 4. Vibration component a versus cutting speed $v_{c}$ and feed per tooth $f_{z}^{y}-$ MLP 3-6-1

components can be used to create a decision support computer system. In this study, the model variables are: cutting speed $\mathrm{v}_{\mathrm{c}}$, feed per tooth $\mathrm{f}_{\mathrm{z}}$, cutting depth $\mathrm{a}_{\mathrm{p}}$. By selecting suitable machining parameters, it is possible to ensure a stable machining range, which leads to enhanced efficiency of the machining process, higher surface quality and decreased tool wear.

\section{CONCLUSIONS}

The results of the conducted analytical and experimental research lead to the following general conclusions:

1. Artificial neural networks are advanced techniques for the modelling of machining dynamics. They can be used for, i.a., predicting nonlinear machining processes such as milling.

2. Given that vibration has a significant effect on the machining process stability, the selec-

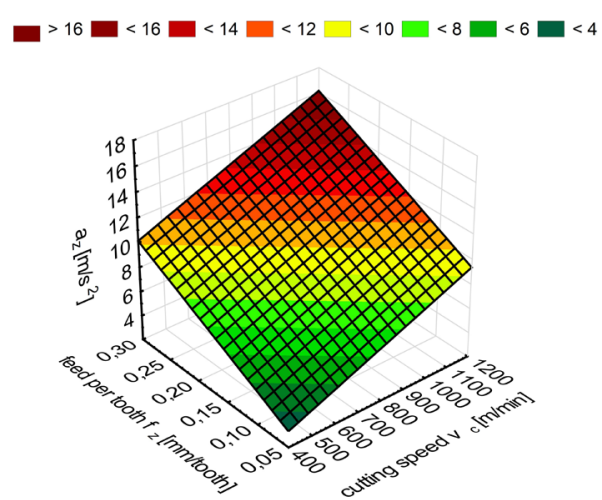

Fig. 5. Vibration component $a_{z}$ versus cutting speed $v_{c}$ and feed per tooth $\mathrm{f}_{\mathrm{z}}-$ MLP 3-4-1

tion of suitable technological parameters leads to the optimization of machining conditions, reduced vibration in the machine tool-chuckworkpiece-tool system and more efficient machining.

3. The simulation of vibration components enables the optimization of machining conditions without the necessity of conducting technological tests (time and material saving); they can also prevent tool or workpiece damage (caused by size and shape inaccuracies or high surface roughness) due to preliminary selection of machining parameters for a preproduction batch.

4. Vibration can be regarded as an interference with the process, so simulations are a kind of "regulator" of the process; interference compensation can be omitted in process control owing to the prediction of output values.

5. The simulations do not eradicate the root cause of the problem because vibration is caused not only by technological parameters of the process; they can, however, eliminate the cause of vibration occurring due to incorrect technological parameters.

6. In high-speed machining it is vital to consider dynamic phenomena such as vibration, as this ensures a shorter machining time and process stability at the same time.

\section{REFERENCES}

1. Adamski W.: Manufacturing development strategies in aviation industry. Advances In Manufacturing Science and Technology, 2010, 34(3), 73-84.

2. Asad M., Mabrouki T., Rigal J-F.: Finite-elementbased hybrid dynamic cutting model for aluminium alloy milling. Proceedings of The Institution of 
Mechanical Engineers - Part B - Journal Of Engineering Manufacture, 2010, 224, B1, 1-13.

3. Bąk P.A., Jemielniak K.: Symulacja numeryczna drgań samowzbudnych przy frezowaniu ze zmiennymi w czasie parametrami skrawania. Mechanik, 2015, 12, 10-13.

4. Burek J., Płodzień M.: Wysoko wydajna obróbka części ze stopów aluminium o złożonych kształtach. Mechanik, 2012, 7, 542-549.

5. Comak A., Budak E.: Modeling dynamics and stability of variable pitch and helix milling tools for development of a design method to maximize chatter stability. Precision Engineering, 2017, 47, 459-468.

6. Dombovari Z., Altintas Y., Stepan G.: The effect of serration on mechanics and stability of milling cutters. International Journal of Machine Tools \& Manufacture, 2010, 50, 511-520.

7. Eynian M.: Vibration frequencies instable and unstable milling. International Journal of Machine Tools \& Manufacture, 2015, 90, 44-49.

8. Friedrich J., Hinze Ch., Renner A., Verl A., Lechler A.: Estimation of stability lobe diagrams in milling with continuous learning algorithms. Robotics and Computer-Integrated Manufacturing, 2017, 43, 124-134.

9. Heo E.Y., Merdol D., Altintas Y.: High speed pocketing strategy. CIRP Journal of Manufacturing Science and Technology, 2010, 3, 1-7.

10. Kasprowiak M., Parus A.: Weryfikacja skuteczności działania aktywnego narzędzia do obniżenia poziomu drgań $\mathrm{w}$ trakcie obróbki podatnym narzędziem. Mechanik,2014, 8-9, 39-46.

11. Kulisz M., Zagórski I., Semeniuk A.: Artificial neural network modelling of cutting force components during AZ91HP alloy milling. Applied Computer Science, 12, 4, 49-58.

12. Munoa J., Beudaert X., Dombovari Z., Altintas Y., Budak E., Brecher C., Stepan G.: Chatter suppression techniques in metal cutting. CIRP Journal of Manufacturing Science and Technology, 2016, 65, 785-808.

13. Oczoś K.E.: Rozszerzenie granic stosowalności stopów magnezu. Mechanik, 2009, 5-6, 386-400.
14. Quintana G., Ciurana J.: Chatter in machining processes: A review. International Journal of Machine Tools \&Manufacture, 2011, 51, 363-376.

15. Rusinek R., Kęcik K., Warmiński J., Weremczuk A.: Dynamic model of cutting process with modulated spindle speed. AIP Conference Proceedings, 2012, 1493(1), 805-809.

16. Rusinek R., Weremczuk A., Warmiński J.: Wpływ nieliniowości w układzie skrawania na skuteczność redukcji drgań samowzbudnych. Mechanik, 2014, 8-9, 81-88.

17. Rusinek R., Zaleski K.: Dynamics of thin-walled element milling expressed by recurrence analysis. Meccanica, 2016, 51, 1275-1286.

18. Rusinek R.: Stability criterion for aluminium alloy milling expressed by recurrence plot measures. Proceedings of the Institution of Mechanical Engineers Part B-Journal of Engineering Manufacture, 2012, 226, A12, 1976-1985.

19. Szaleniec, M.: Sieci Neuronowe i regresja wieloraka - czyli jak okiełznać złożoność w badaniach naukowych. Retrieved from (2016, October 11) http:// www.statsoft.pl/Portals/0/Downloads/Sieci\%20 neuronowe.pdf

20. Weremczuk A., Rudzik M., Rusinek R., Warmiński J.: The concept of active elimination of vibrations in milling process. Procedia CIRP, 2015, 31, 82-87.

21. Weremczuk A., Rusinek R., Warmiński J.: Koncepcja aktywnej eliminacji drgań w procesie frezowania. Mechanik, 2014, 7-8, 99-105.

22. Wu S., Li R., Liu X., Yang L., Zhu M.: Experimental study of thin wall milling chatter stability nonlinear criterion. Procedia CIRP, 2016, 56, 422 - 427.

23. Yang Y., Zhang W-H., Ma Y-Ch., Wan M.: Chatter prediction for the peripheral milling of thin-walled workpieces with curved surfaces. International Journal of Machine Tools \&Manufacture, 2016, 109, 36-48.

24. Yusoff A. R.: Identifying bifurcation behavior during machining process for an irregular milling tool geometry. Measurement,2016, 93, 57-66.

25.Żyłka Ł., Płodzień M.: Stabilność 5-osiowego frezowania stopów aluminium. Mechanik, 2013, $2,1-12$ 